EXTENDED REPORT

\title{
ARIX gene polymorphisms in patients with congenital superior oblique muscle palsy
}

\author{
Y Jiang, T Matsuo, H Fujiwara, S Hasebe, H Ohtsuki, T Yasuda
}

Br J Ophthalmol 2004;88:263-267. doi: 10.1136/bjo2003.021527

See end of article for authors' affiliations

Correspondence to: Toshihiko Matsuo, MD $\mathrm{PhD}$, Department of Ophthalmology, Faculty of Medicine, Okayama University Graduate School of Medicine and Dentistry, Okayama City 700-8558, Japan; matsuot@

cc.okayama-u.ac.jp

Accepted for publication 12 May 2003

\begin{abstract}
Aim: To identify ARIX gene polymorphisms in patients with congenital superior oblique muscle palsy and to find the relation between the ARIX gene and congenital superior oblique muscle palsy.

Methods: The three exons of the ARIX gene were sequenced by genomic DNA amplification with polymerase chain reaction (PCR) and direct sequencing in 15 patients with superior oblique muscle palsy (13 with congenital and two with acquired palsy) and 54 normal individuals. PCR products cloned into plasmids were also sequenced. A family with father and a daughter each having congenital superior oblique muscle palsy was also involved in this study.

Results: Four patients with congenital superior oblique muscle palsy carried heterozygous nucleotide changes in the ARIX gene. One patient with the absence of the superior oblique muscle had T7C in the 5' UTR of the exon 1 and C-44A in the promoter region, both of which were located on the same strand. Another unrelated patient with congenital superior oblique muscle palsy had C76G in the 5'-UTR of the exon 1 and C-9A in the promoter region on the same strand. G153A in the $5^{\prime}$-UTR of exon 1 was found in common in two affected members of a family with congenital superior oblique muscle palsy. This G153A in the $5^{\prime}$-UTR of exon 1 was also present in four unrelated normal individuals. No other heterozygous nucleotide changes were found in normal individuals.

Conclusions: The nucleotide change (G153A) in the $5^{\prime}$-UTR of exon 1 co-segregated with congenital superior oblique muscle palsy in one family. Four other nucleotide changes in the exon 1 or the promoter region were found only in patients with congenital superior oblique muscle palsy. These nucleotide polymorphisms may be one of the risk factors for the development of congenital superior oblique muscle palsy.
\end{abstract}

$\mathrm{S}$ uperior oblique muscle palsy is the most frequent isolated cranial nerve palsy encountered in strabismology. ${ }^{1}$ In addition, it is probably the most common cause of vertical deviation in the primary gaze. Congenital superior oblique muscle palsy has a high incidence, accounting for $25 \%$ to $44 \%$ of cases. ${ }^{1-3}$ Although the true aetiology of congenital superior oblique muscle palsy remains speculative, possible causes include hypoplasia of the trochlear nucleus or nerve, perinatal nerve injury, and anatomical defects of the superior oblique tendon or the trochlea. ${ }^{3-7}$ Until now, familial aggregation of congenital superior oblique muscle palsy has been occasionally reported, but its genetic cause has not yet been studied..$^{8-11}$

Congenital fibrosis of the extraocular muscles (CFEOM), characterised by congenital ptosis and restrictive external ophthalmoplegia, is a clinical entity of the congenital ocular motility disorder that arises probably from dysfunction of the oculomotor, trochlear, and abducens nerves and atrophy of the extraocular muscles which these nerves innervate. ${ }^{12}{ }^{13}$ CFEOM2 is a subtype in which the patients have bilateral ptosis and ophthalmoplegia with their eyes partially or completely fixed in an exotropic position, or mildly in a hypertropic or hypotropic position. ${ }^{14}$ Recently, mutations of ARIX, a homeobox-containing gene, have been found in families with CFEOM2. ${ }^{15}$ ARIX is indeed expressed in the brainstem nuclei for oculomotor and trochlear nerves. ${ }^{16}{ }^{17}$ Based on the facts that the superior oblique muscle is involved in CFEOM and that $A R I X$ is expressed in the trochlear nucleus, we hypothesise that congenital superior oblique muscle palsy may be a milder variant of CFEOM. In the present study, we analysed ARIX gene polymorphisms in patients with superior oblique muscle palsy and normal individuals to find whether the ARIX gene might be related to congenital superior oblique muscle palsy. We also showed an ARIX gene polymorphism which co-segregated with congenital superior oblique muscle palsy in one family.

\section{PATIENTS AND METHODS}

The study included 15 patients in whom a diagnosis of superior oblique muscle palsy was made: 13 with congenital palsy and two with acquired palsy. All patients were questioned about the age at onset, a history of previous head trauma, and family history of strabismus. Clinical examinations included visual acuity, inspection of head posture, deviation measurement at 5 metres and 0.3 metre by alternate prism and cover test in nine diagnostic positions of the gaze, version, Bielschowsky head tilt test, vertical fusional amplitude, and TNO stereotest. Orbital magnetic resonance imaging was performed in all patients to evaluate the status of the superior oblique muscle except one patient (case 13 in table 1). Fifty four normal individuals who were confirmed as having no ophthalmological diseases also participated in this study. All patients and normal individuals were ethnic Japanese. In one family with father and a daughter, each having congenital superior oblique muscle palsy, unaffected members also participated (fig 1). The study was approved by the institutional review board at Okayama University Hospital, and written consent was obtained from each patient or parent when the patient was below the age of 15. All the procedures conformed to the Declaration of Helsinki.

Genomic DNA of 15 patients and 54 normal individuals was used for the study. Briefly, peripheral leucocytes were isolated from $10 \mathrm{ml}$ blood by gradient centrifugation and genomic DNA was purified by phenol/chloroform extraction and methanol precipitation. Five sets of primers were used to 
Table 1 Clinical characteristics of patients with congenital and acquired superior oblique muscle palsy and nucleotide changes in the ARIX gene

\begin{tabular}{|c|c|c|c|c|c|c|c|c|c|c|c|}
\hline \multirow[b]{2}{*}{$\begin{array}{l}\text { Case } \\
\text { No }\end{array}$} & \multirow[b]{2}{*}{ Sex } & \multirow[b]{2}{*}{$\begin{array}{l}\text { Age at } \\
\text { onset }\end{array}$} & \multirow[b]{2}{*}{ Eye } & \multirow[b]{2}{*}{$\begin{array}{l}\text { Past } \\
\text { history }\end{array}$} & \multirow[b]{2}{*}{$\begin{array}{l}\text { Family } \\
\text { history }\end{array}$} & \multirow{2}{*}{$\begin{array}{l}\text { Deviation at } \\
\text { far (prism } \\
\text { dioptres) }\end{array}$} & \multirow{2}{*}{$\begin{array}{l}\text { Magnetic } \\
\text { resonance } \\
\text { imaging }\end{array}$} & \multicolumn{2}{|l|}{ Surgical procedure } & \multicolumn{2}{|c|}{ Nucleotide changes } \\
\hline & & & & & & & & First & Second & Promoter & $\begin{array}{l}5^{\prime} \text {-UTR of } \\
\text { exon } 1\end{array}$ \\
\hline 1 & $\mathrm{~F}$ & 12 years & $\mathrm{L}$ & No & No & 25LHT/16XT & LSO atrophy & $\begin{array}{l}\text { LIO recess } 10 \mathrm{~mm} \\
\text { LLR recess } 6 \mathrm{~mm}\end{array}$ & & & \\
\hline 2 & $M$ & 3 months & $\mathrm{L}$ & No & No & 14LHT/4XT & Normal & LIO recess $10 \mathrm{~mm}$ & & & \\
\hline $3 \dagger$ & $\mathrm{F}$ & Childhood & $\mathrm{R}$ & No & $\begin{array}{l}\text { Father: RE, } \\
\text { SOP }\end{array}$ & 25RHT/10XT & Normal & $\mathrm{RIO}$ recess $10 \mathrm{~mm}$ & & & G153A \\
\hline $4 \dagger$ & $M$ & $40 \mathrm{~s}$ & $\mathrm{R}$ & No & $\begin{array}{l}\text { Daughter: } \\
\text { RE, SOP }\end{array}$ & $30 \mathrm{RHT} / 6 \mathrm{XT}$ & RSO atrophy & LIR recess $4 \mathrm{~mm}$ & & & G153A \\
\hline 5 & $\mathrm{~F}$ & 3 months & $\mathrm{R}$ & No & $\begin{array}{l}\text { Aunt: } \\
\text { hypertropia }\end{array}$ & 25RHT/14XT & RSO atrophy & $\begin{array}{l}\mathrm{RIO} \text { recess } 10 \mathrm{~mm} \\
\mathrm{RSR} \text { recess } 3 \mathrm{~mm}\end{array}$ & $\begin{array}{l}\text { LIR recess } 3 \mathrm{~mm} \\
\text { LLR recess } 6 \mathrm{~mm}\end{array}$ & & \\
\hline 6 & $M$ & 8 years & $\mathrm{L}$ & No & No & 10LHT/4XT & Normal & LIO recess $10 \mathrm{~mm}$ & & & \\
\hline $7^{*}$ & $M$ & Childhood & $\mathrm{R}$ & No & No & 35RHT/6ET & RSO absence & $\mathrm{RIO}$ recess $14 \mathrm{~mm}$ & $\begin{array}{l}\text { LIR recess } \\
\text { LIR recess } \\
3.5 \mathrm{~mm} \\
\text { LSR resect } \\
3,5 \mathrm{~mm}\end{array}$ & C-44A $\ddagger$ & T7C \\
\hline 8 & $M$ & 4 months & $\mathrm{R}$ & No & No & 10RHT & Normal & $\mathrm{RIO}$ recess $5 \mathrm{~mm}$ & & & \\
\hline 9 & $\mathrm{~F}$ & $20 s$ & $\mathrm{R}$ & No & No & 16RHT/14XT & Normal & $\mathrm{RIO}$ recess $10 \mathrm{~mm}$ & & & \\
\hline 10 & $M$ & 3 years & $\mathrm{L}$ & No & No & 8LHT/2XT & LSO atrophy & $\mathrm{LO}$ recess $10 \mathrm{~mm}$ & & & \\
\hline 11 & $\mathrm{~F}$ & 3 months & $\mathrm{L}$ & No & No & 10LHT/6XT & LSO atrophy & LIO recess $10 \mathrm{~mm}$ & & & \\
\hline 12 & $\mathrm{~F}$ & Birth & $\mathrm{R}$ & No & No & 10RHT/6XT & Normal & $\begin{array}{l}\text { RIO recess } 4 \mathrm{~mm} \\
\text { RSR recess } 3 \mathrm{~mm}\end{array}$ & & C-9A & C76G $\ddagger$ \\
\hline 13 & $M$ & 2 years & $\mathrm{R}$ & No & No & $8 \mathrm{RHT} / 30 \mathrm{XT}$ & NA & $\begin{array}{l}\text { RLR recess } 5 \mathrm{~mm} \\
\text { RMR resect } 5 \mathrm{~mm}\end{array}$ & & & \\
\hline 14 & $\mathrm{~F}$ & 60 years & $\mathrm{L}$ & $\begin{array}{l}\text { SAH } \\
\text { operation }\end{array}$ & No & 16LHT/6XT & LSO atrophy & $\mathrm{LIO}$ recess $10 \mathrm{~mm}$ & RIR recess $3 \mathrm{~mm}$ & & \\
\hline 15 & $\mathrm{~F}$ & 38 years & $\mathrm{L}$ & $\begin{array}{l}\text { Traffic } \\
\text { accident }\end{array}$ & No & 25LHT/8XT & LSO atrophy & LIO recess $10 \mathrm{~mm}$ & & & \\
\hline
\end{tabular}

$\mathrm{NA}=$ not available; $\mathrm{SAH}=$ subarachnoid haemorrhage; $\mathrm{LHT}=$ left hypertropia; $\mathrm{RHT}=$ right hypertropia; $\mathrm{XT}=$ exotropia; $\mathrm{ET}=$ esotropia; $\mathrm{LSO}=$ left superior oblique; $L I O=$ left inferior oblique; $L L R=$ left lateral rectus; $L I R=$ left inferior rectus; $L S R=$ left superior rectus; RIO = right inferior oblique; RSO = right superior oblique; RSR = right superior rectus; RLR = right lateral rectus; RIR = right inferior rectus; RMR = right medial rectus; $S O P=$ superior oblique muscle palsy. *Patient with superior oblique muscle and trochlea absence. TFather and daughter with superior oblique muscle palsy. $\ddagger$ These two changes are located on the same strand.

Cases 1-13 represent patients with congenital superior oblique muscle palsy and cases 14 and 15 represent the patients with acquired superior oblique muscle palsy.

amplify exons 1, 2, and 3 of the ARIX gene from $100 \mathrm{ng}$ of genomic DNA. Polymerase chain reaction (PCR) was carried out with HotStarTaq DNA polymerase (Qiagen, Hilden, Germany): initial denaturation at $95^{\circ} \mathrm{C}$ for 15 minutes, followed by 35 cycles at $94^{\circ} \mathrm{C}$ for 40 seconds, at $56-60^{\circ} \mathrm{C}$ for 1 minute, and at $72^{\circ} \mathrm{C}$ for 1 minute, and final extension at $72^{\circ} \mathrm{C}$ for 10 minutes. PCR products were purified with Geneclean DNA Purification Kit (Qbiogene, Montreal, Canada) and used as a template for direct sequencing with ABI 310 Genetic Analyser (PE-Applied Biosystems, CA, USA)

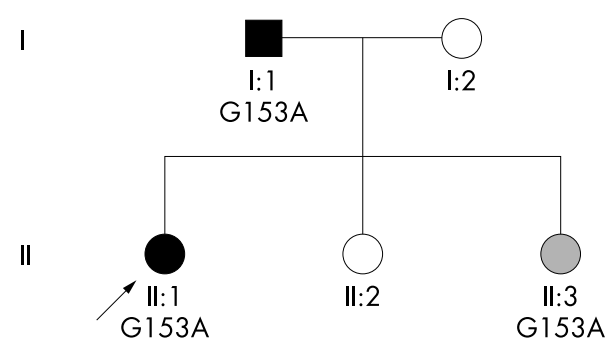

Figure 1 Pedigree of a family with congenital superior oblique muscle palsy (SOP) in this study. Squares and circles refer to males and females, respectively. Solid symbols $=$ affected individuals; open symbols $=$ normal individuals. Hatched circle represents an asymptomatic individual who happens to have a change. The arrow points to the proband. Roman and Arabic numerals indicate generations and position of individuals within generations, respectively. Nucleotide change is shown below the symbol. In this family, both father (I:1) and his eldest daughter (II:1) harbour G153A in the 5'-UTR of the exon 1 of ARIX gene, co-segregating with their phenotypes. His youngest daughter (II:3) also harbours this nucleotide change without any symptoms at this time. using BigDye Terminator Cycle Sequencing Kit (PE-Applied Biosystems). Both strands were sequenced for each DNA fragment. DNA sequences were aligned with the published human ARIX sequences (GenBank Accession Numbers: AF022722, AF022723, and AF022724). To examine whether nucleotide changes were located on the same strand or not, PCR products were cloned into plasmids using TOPO TA Cloning Kit (Invitrogen, CA, USA) and sequenced.

\section{RESULTS}

The characteristics of 15 patients with superior oblique muscle palsy are summarised in table 1 . Of the 15 patients with superior oblique muscle palsy, 13 were diagnosed with congenital superior oblique muscle palsy, while two were diagnosed with acquired superior oblique muscle palsy, which was preceded by traffic accident and subarachnoid haemorrhage surgery, respectively.

Several common homozygous changes, compared with the GenBank sequence, were found in the ARIX gene of all 15 superior oblique muscle palsy patients and 54 normal individuals as follows (not shown in fig 2): A393C and T399G in exon 2, A636G, A666G, A672G, A690G, T960C, A978C, and T1020C in exon 3, which were not responsible for amino acid substitutions except for T399G producing a single amino acid substitution (Asn76Lys). In addition, common changes found in intron 1 of the ARIX gene in all patients and normal individuals were T-63C, T-60C, T-57C, G-54C, A-52C, T-50C, G-40C, A-16 C, and G-13C (not shown in fig 2, nucleotide numbers in the intron 1 assigned relative to the beginning of the exon 2).

Among the 13 patients with congenital superior oblique muscle palsy, four had heterozygous nucleotide changes in 


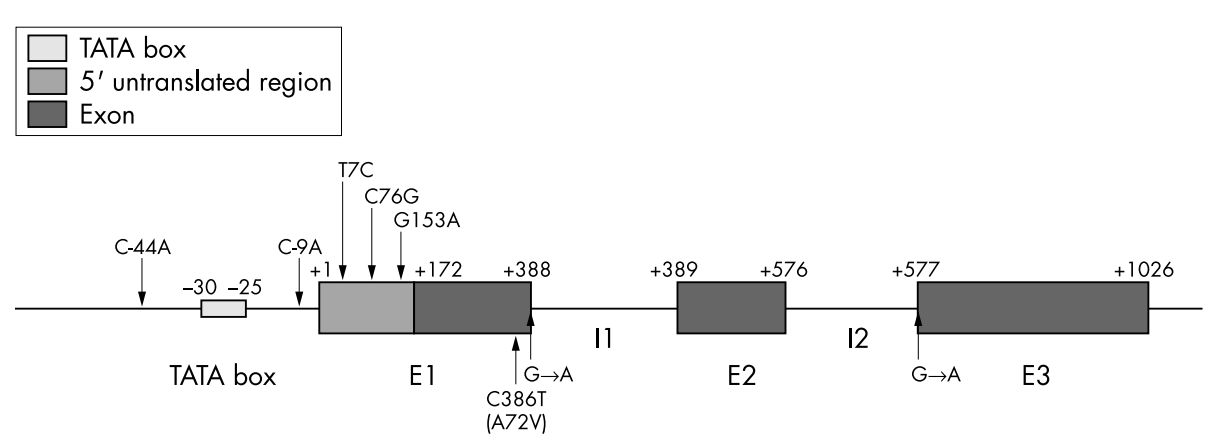

Figure 2 Nucleotide changes of ARIX gene in patients with congenital superior oblique muscle palsy (above the line) in this study and CFEOM2 patients (below the line) reported previously. ${ }^{15}$ The numbering system indicates the position of the sequence of the ARIX mRNA (GenBank accession number: NM-005169) and all nucleotide numbers are assigned relative to the transcription start site. The positions of nucleotide changes are pointed out by arrows and changed nucleotides are shown. T7C in the $5^{\prime}$-UTR of exon 1 and C-44A in the promoter region occur in one patient with congenital superior oblique muscle absence. C76G in the $5^{\prime}$-UTR of exon 1 and C-9A in the promoter region occur in another unrelated patient with congenital superior oblique muscle palsy. G153A in the $5^{\prime}$-UTR of exon 1 was found in common in two members with congenital superior oblique muscle palsy in a family. In contrast with $A R I X$ nucleotide changes in patients with congenital superior oblique muscle palsy, mutations in CFEOM2 patients are shown at the bottom of the figure: C386T with an amino acid substitution of Ala72Val (shown in parentheses), $G$ to $A$ change at position +1 of the GT splice donor sequence of exon 1 , and $G$ to $A$ change at position - 1 of the $A G$ splice acceptor site of exon 3 .

the ARIX gene (table 1, fig 2). One patient (case 7) with the absence of the superior oblique muscle had T7C in the $5^{\prime}$-UTR of exon 1 and $\mathrm{C}-44 \mathrm{~A}$ in the promoter region, both of which were located on the same strand of genomic DNA. Another unrelated patient (case 12) with congenital superior oblique muscle palsy who showed the normal muscle on magnetic resonance imaging had C76G in the $5^{\prime}$-UTR of exon 1 and C$9 \mathrm{~A}$ in the promoter region on the same strand. These changes were absent in the 54 normal individuals. The combination of such nucleotide changes in the $5^{\prime}$-UTR and the promoter region reached statistical significance $(p=0.0353$, Fisher's exact probability test) between two of the 13 patients with congenital superior oblique muscle palsy and none of the 54 normal individuals).

Both father (case 4) and his eldest daughter (case 3) having congenital superior oblique muscle palsy as a common manifestation in one family were found to harbour a heterozygous nucleotide change of G153A in the 5'-UTR of exon 1. This change was also found in his unaffected youngest daughter as well as in four of the 54 normal individuals (table 1, fig 1). The daughter showed the normal superior oblique muscle on magnetic resonance imaging while the father showed atrophy of the muscle. Two patients diagnosed with acquired superior oblique muscle palsy in this study did not carry any nucleotide changes. The 54 normal individuals did not have the other heterozygous nucleotide changes except for four with G153A in the 5'-UTR of exon 1 as mentioned above.

\section{DISCUSSION}

In the present study, several homozygous cosense changes in exons 2 and 3 of the ARIX gene in all patients and normal individuals were found in comparison with the GenBank sequence. These changes would be common traits in the Japanese population or errors in the initial sequence. In addition, one homozygous missense change of T399G (Asn76Lys) was detected as a common trait in exon 2 of all patients and normal individuals. This change of Asn76Lys is located beyond the brachyury-like domain which is a short peptide sequence (amino acids 61-75) of ARIX with high conservation. ${ }^{18}{ }^{19}$ Nakano and coworkers ${ }^{15}$ also proved that the sequence of ARIX analysed in their patients and normal individuals differed from the published sequence at the same T399G which altered an amino acid from Asn to Lys and brought the human sequence in agreement with that of the mouse and rat, providing additional evidence that this
Asn76Lys is a polymorphism. Similarly, several changes in intron 1 of ARIX gene, which exist in all participants, are considered as ARIX gene polymorphisms.

Two kinds of the unique combinations of heterozygous nucleotide changes in the promoter region and the 5'-UTR of the same genomic DNA strand were found separately in two patients with congenital superior oblique muscle palsy. These changes were absent in the 54 normal individuals. Furthermore, it should be noted that one (case 7) of the two patients showed congenital absence of the superior oblique muscle. The $5^{\prime}$-UTR is involved in the binding of the 40S ribosomal subunit to the mRNA at the internal ribosomal entry site and subsequent scanning along the 5'-UTR region until the initiation codon is reached. Mutations in the $5^{\prime}$-UTR sequence indeed inhibit the initiation of translation. $^{20-22}$ On the other hand, mutations in the promoter region reduce promoter activity and lead to downregulation of the transcription. ${ }^{23}{ }^{24}$ The combinations of nucleotide changes in the promoter region and the 5'-UTR of exon 1 found in the present study are presumed to reduce ARIX transcription and translation, giving rise to low levels of the normal protein.

ARIX, a homeobox-containing gene, is expressed in the brainstem nuclei for oculomotor and trochlear nerve which control eye movement, and encodes a homeodomain transcription factor protein previously shown to be required for oculomotor and trochlear nerve development in mouse and zebrafish. $^{16} 172526$ Nakano and coworkers ${ }^{15}$ reported ARIX mutations in the exon 1 as well as in two separate splice sites in CFEOM2 patients, which were predicted to disrupt a highly conserved subdomain of ARIX and the transcript upstream of its homeodomain region, respectively, concluding ARIX as the gene causing CFEOM2 (fig 2).

The trochlear nerve was the last of the ocular motility nerves to reach its innervated muscle, and such developmental handicap of the trochlear nerve and nucleus could conceivably result in isolated trochlear nerve palsy. Based on this fact, congenital superior oblique muscle palsy, not only as a milder variant of CFEOM but also as congenital isolated trochlear nerve palsy, is suspected to be related to the ARIX gene which regulates the development of the trochlear nerve and nucleus. Compared with the ARIX mutations in CFEOM2 patients, one with an amino acid substitution and two in the separate splice sites (fig 2), which resulted in abnormal or truncated proteins, the ARIX gene polymorphisms found in the two patients with congenital superior oblique muscle 
palsy would only give rise to reduced levels of the normal protein. Such differences in putative proteins would explain why the nucleotide changes in the same ARIX gene lead to severe clinical manifestations as CFEOM2 on one occasion and to such milder clinical features as isolated superior oblique muscle palsy on the other occasions.

The nucleotide change, G153A in the 5'-UTR of exon 1, was found in common in a father and his eldest daughter of a family with congenital superior oblique muscle palsy in this study. Despite such co-segregation of superior oblique muscle palsy with the nucleotide change, the youngest daughter in this family and four normal individuals also harboured the change. So it is possible that this G153A is a non-pathogenic change co-segregating with congenital superior oblique muscle palsy by chance as a polymorphism. The youngest daughter was asymptomatic and clinical examinations revealed no sign of superior oblique muscle palsy at the age of 20 when her family members were analysed in this study. The previous reports indicate that congenital superior oblique muscle palsy is an autosomal dominant disorder but that some patients might be asymptomatic and underdiagnosed. ${ }^{8-}$ ${ }^{10}$ We cannot, therefore, exclude a possibility that the youngest daughter might have a subtle change of the superior oblique muscle and tendon as an asymptomatic carrier, which would, later in her life, produce superior oblique muscle palsy.

In the present study, only four patients with congenital superior oblique muscle palsy were found to carry nucleotide changes in the ARIX gene. Since we sequenced mainly the three exons and the splicing sites of the ARIX gene, we might miss other changes in the introns (about two thirds of the intron 1 and 2 were not sequenced) or $3^{\prime}$-UTR which would be responsible for congenital superior oblique muscle palsy in other patients. Furthermore, the other genes may be responsible for congenital superior oblique muscle palsy in the case that the ARIX gene is considered as only one of genetic risk factors for the disease. For example, PHOX2B, a close relative of ARIX (also known as PHOX2A) with an identical homeodomain, is co-expressed with $A R I X$ at most sites, such as in the branchiomotor and visceral motor neurons, in the oculomotor and trochlear nuclei, and in the adrenergic and noradrenergic centres such as the locus coeruleus, visceral sensory and parasympathetic ganglia. ${ }^{27} 28$ Based on the facts that the oculomotor and trochlear nuclei are present in $\mathrm{PHOX}_{2} \mathrm{~B}^{-/-}$mice, ${ }^{29}$ but absent in $A R I X^{-1-}$ mice, ${ }^{1725}$ both oculomotor and trochlear nuclei would consist mainly of ARIX dependent neurons and would not necessarily require PHOX2B for the normal development. ${ }^{15}$ In contrast, cross regulation and interaction do occur between ARIX and PHOX2B, ${ }^{25}{ }^{30}{ }^{31}$ suggesting that PHOX2B also has a role in the normal development of these nuclei.

The patients with congenital superior oblique muscle palsy do not show obvious signs and symptoms of dysfunction in the other areas of the central nervous system, including the locus coeruleus and parasympathetic ganglia. Such clinical facts are inconsistent with the broader areas of ARIX expression. One explanation would be that ARIX may not be essential for the development of the locus coeruleus and parasympathetic ganglia, possibly because PHOX2B or the other analogues specify the development of these neurons. ${ }^{15}{ }^{32}$ Alternatively, dysfunction in the other areas would be clinically insignificant or silent even if these neurons are abnormal in individuals with congenital superior oblique muscle palsy. ${ }^{15}$ Further studies of ARIX and PHOX2B genes are needed to explain this discrepancy.

In conclusion, the ARIX gene polymorphisms may be one of genetic risk factors for the development of congenital superior oblique muscle palsy. Since congenital superior oblique muscle palsy may comprise multiple pathogenic diseases, other contributing factors, either genetic or environmental, may come into play in addition to the ARIX gene. Further analysis of a large number of patients with congenital superior oblique muscle palsy is necessary to reach the final conclusion because of a small sample size in this study.

\section{ACKNOWLEDGEMENTS}

The authors thank Dr Elizabeth C Engle for providing information of the primers for ARIX gene.

\section{Authors' affiliations}

Y Jiang, T Matsuo, H Fujiwara, S Hasebe, H Ohtsuki, Department of Ophthalmology Faculty of Medicine, Okayama University Graduate School of Medicine and Dentistry, Okayama City, Japan

Y Jiang, T Yasuda, Department of Cell Chemistry, Faculty of Medicine, Okayama University Graduate School of Medicine and Dentistry,

Okayama City, Japan

\section{REFERENCES}

1 Ellis FD, Helveston EM. Superior oblique palsy: diagnosis and classification. Int Ophthalmol Clin 1976;16:127-35.

2 Von Noorden GK, Murray E, Wong SY. Superior oblique paralysis. A review of 270 cases. Arch Ophthalmol 1986;104:1771-6.

3 Helveston EM, Krach D, Plager DA, et al. A new classification of superior oblique palsy based on congenital variations in the tendon. Ophthalmology 1992;99:1609-15.

4 Matsuo T, Ohtsuki $H$, Sogabe $Y$, et al. Vertical abnormal retinal correspondence in three patients with congenital absence of the superior oblique muscle. Am J Ophthalmol 1988;106:341-5.

5 Mansour AM, Reinecke RD. Central trochlear palsy. Surv Ophthalmol 1986;30:279-97

6 Chan TK, Demer JL. Clinical features of congenital absence of the superior oblique muscle as demonstrated by orbital imaging. J AAPOS 1999:3:143-50.

7 Sato M. Magnetic resonance imaging and tendon anomaly associated with congenital superior oblique palsy. Am J Ophthalmol 1999;127:379-87.

8 Bhola RM, Horne GV, Squirrell DM, et al. Autosomal dominant congenital superior oblique palsy. Eye 2001;15:479-84.

9 Botelho PJ, Giangiacomo JG. Autosomal-dominant inheritance of congenital superior oblique palsy. Ophthalmology 1996;103:1508-11.

10 Harris DJ Jr, Memmen JE, Katz NN, et al. Familial congenital superior oblique palsy. Ophthalmology 1986;93:88-90.

11 Astle WF, Rosenbaum AL. Familial congenital fourth cranial nerve palsy. Arch Ophthalmol 1985;103:532-5.

12 Engle EC. Applications of molecular genetics to the understanding of congenital ocular motility disorders. Ann N Y Acad Sci 2002;956:55-63.

13 Engle EC, Mclntosh N, Yamada K, et al. CFEOM1, the classic familial form of congenital fibrosis of the extraocular muscles, is genetically heterogeneous but does not result from mutations in ARIX. BMC Genet 2002;3:3.

14 Wang SM, Zwaan J, Mullaney PB, et al. Congenital fibrosis of the extraocular muscles type 2, an inherited exotropic strabismus fixus, maps to distal 11 q13. Am J Hum Genet 1998;63:517-25.

15 Nakano M, Yamada K, Fain J, et al. Homozygous mutations in ARIX(PHOX2A) result in congenital fibrosis of the extraocular muscles type 2. Nat Genet $2001 ; 29: 315-20$.

16 Zellmer E, Zhang Z, Greco D, et al. A homeodomain protein selectively expressed in noradrenergic tissue regulates transcription of neurotransmitter biosynthetic genes. J Neurosci 1995;15:8109-20.

17 Morin X, Cremer H, Hirsch MR, et al. Defects in sensory and autonomic ganglia and absence of locus coeruleus in mice deficient for the homeobox gene Phox2a. Neuron 1997;18:411-23.

18 Swanson DJ, Adachi M, Lewis EJ. The homeodomain protein Arix promotes protein kinase A-dependent activation of the dopamine beta-hydroxylase promoter through multiple elements and interaction with the coactivator cAMP-response element-binding protein-binding protein. J Biol Chem 2000;275:2911-23.

19 Adachi M, Browne D, Lewis EJ. Paired-like homeodomain proteins Phox2a/ Arix and Phox $2 \mathrm{~b} / \mathrm{NBPh}$ ( have similar genetic organization and independently regulate dopamine beta-hydroxylase gene transcription. DNA Cell Biol 2000; 19:539-54.

20 Saxena A, Moshynska O, Sankaran K, et al. Association of a novel single nucleotide polymorphism, G(-248)A, in the 5'-UTR of BAX gene in chronic lymphocytic leukemia with disease progression and treatment resistance. Cancer Lett 2002:187:199-205.

21 Clemens MJ, Bommer UA. Translational control: the cancer connection. Int J Biochem Cell Biol 1999;31:1-23.

22 Meijer HA, Thomas AA. Control of eukaryotic protein synthesis by upstream open reading frames in the $5^{\prime}$-untranslated region of an mRNA. Biochem $J$ 2002;367:1-11. 
23 Van Wijk R, Van Solinge WW, Nerlov C, et al. Disruption of a novel regulatory element in the erythroid-specific promoter of the human PKLR gene causes severe pyruvate kinase deficiency. Blood 2003;101:1596-602.

$24 \mathrm{Kim} \mathrm{SW}$, Lee SH, Kim KS, et al. Isolation and characterization of the promoter region of the human GM3 synthase gene. Biochim Biophys Acta 2002; 1578:84-9.

25 Pattyn A, Morin X, Cremer H, et al. Expression and interactions of the two closely related homeobox genes Phox $2 a$ and Phox $2 b$ during neurogenesis. Development 1997;124:4065-75.

26 Guo S, Brush J, Teraoka H, et al. Development of noradrenergic neurons in the zebrafish hindbrain requires BMP, FGF8, and the homeodomain protein soulless/Phox2a. Neuron 1999;24:555-66.

27 Pattyn A, Hirsch M, Goridis C, et al. Control of hindbrain motor neuron differentiation by the homeobox gene Phox $2 b$. Development 2000; 127:1349-58.
28 Tiveron MC, Hirsch MR, Brunet JF. The expression pattern of the transcription factor Phox2 delineates synaptic pathways of the autonomic nervous system. J Neurosci 1996;16:7649-60.

29 Pattyn A, Morin X, Cremer H, et al. The homeobox gene Phox $2 b$ is essentia for the development of autonomic neural crest derivatives. Nature 1999:399:366-70

30 Flora $A$, Lucchetti $H$, Benfante R, et al. SP proteins and Phox $2 b$ regulate the expression of the human Phox2a gene. J Neurosci 2001;21:7037-45.

31 Hong SJ, Kim CH, Kim KS. Structural and functional characterization of the 5 upstream promoter of the human Phox2a gene: possible direct transactivation by transcription factor Phox $2 b$. J Neurochem 2001;79:1225-36.

32 Pattyn A, Goridis C, Brunet JF. Specification of the central noradrenergic phenotype by the homeobox gene Phox $2 \mathrm{~b}$. Mol Cell Neurosci $2000 ; 15: 235-43$.

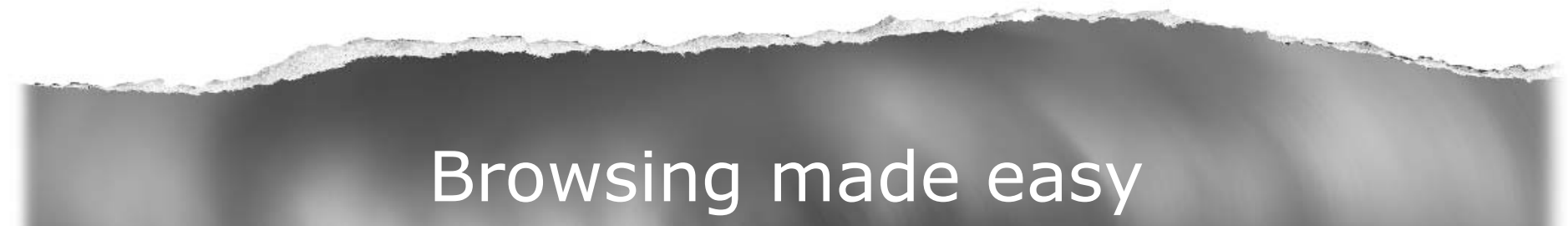

\section{Collections}

With a single click Collections allows you to find all articles that have been published in your chosen subject. Select from over 200 clinical and non-clinical topic collections and/or cross search other specialist journals, the BMJ and Cochrane Reviews

\section{www.bjophthalmol.com}

